Revista Bioética

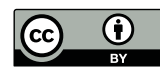

Print version ISSN 1983-8042 On-line version ISSN 1983-8034

Rev. Bioét. vol.27 no.4 Brasília Out./Dez. 2019

Doi: 10.1590/1983-80422019274343

\title{
ATUALIZAÇÃO
}

\section{Assuntos inacabados: relato de encontro e rito de passagem}

Adriana Rodrigues da Silva Utida ${ }^{1}$, Alexandre da Silva Faco Junior ${ }^{1}$, Geraldo Karam Joaquim Mousfi ${ }^{1}$

1. Programa de Residência em Clínica Médica, Hospital e Maternidade São José dos Pinhais (HMSJP), São José dos Pinhais/PR, Brasil.

\section{Resumo}

Os cuidados paliativos surgiram na medicina com o intuito de otimizar a assistência médica oferecida ao paciente, visando o alívio dos sintomas e a atenção integral ao indivíduo em si, e não à doença. Por ser especialidade relativamente nova, muitas vezes o profissional dessa área depara-se com situações que não podem ser explicadas simplesmente pelo conhecimento tecnocientífico. A partir de um relato de experiência, este artigo objetiva refletir sobre as circunstâncias envolvidas no período pré-morte.

Palavras-chave: Bioética. Cuidados paliativos. Cuidados paliativos na terminalidade da vida. Espiritualidade.

\section{Resumen}

\section{Asuntos pendientes: relato de encuentro y rito de pasaje}

Los cuidados paliativos surgieron en la medicina con el propósito de optimizar la asistencia médica ofrecida al paciente, tendiendo al alivio de los síntomas y a la atención integral al individuo en sí y no a la enfermedad. Por ser una especialidad relativamente nueva, muchas veces, el profesional de esta área se enfrenta a situaciones que no pueden ser explicadas simplemente por el conocimiento tecnocientífico. A partir del relato de una experiencia, este artículo tiene como objetivo reflexionar acerca de las circunstancias involucradas en el período pre-muerte. Palabras clave: Bioética. Cuidados paliativos. Cuidados paliativos al final de la vida. Espiritualidad.

\section{Abstract}

\section{Unfinished business: report of a meeting and a rite of passage}

Palliative care has arisen in medicine in order to optimize the medical care offered to patients, aiming at the relief of symptoms and holistic care for the individual rather than the disease. Because it is a relatively new specialty, professionals in this field often face situations that cannot be explained simply by technoscientific knowledge. Based on an experience report, this article aims to reflect on the circumstances involved in the pre-death period.

Keywords: Bioethics. Palliative care. Hospice care. Spirituality. 
Além de oferecer cuidado integral ao paciente e possibilitar a ele morte digna de acordo com seus preceitos, a enfermaria de cuidados paliativos expõe a equipe de saúde a certos momentos e condições que envolvem dilemas. O Hospital e Maternidade São José dos Pinhais (HMSJP), situado em São José dos Pinhais, na região metropolitana de Curitiba, Paraná, Brasil, recentemente implementou seu serviço de cuidados paliativos sob a orientação de médica mestre em bioética, e já presenteou sua equipe com alguns desses momentos. "Presenteou" porque são situações que explicitam o fato de que a medicina ainda não pode explicar a natureza das emoções e seu impacto na vida e na morte dos seres humanos.

Desta forma, a partir do relato pré-morte de caso ocorrido na clínica médica do HMSJP em 2018, o intuito deste artigo é exemplificar uma dessas situações, refletindo sobre as circunstâncias que possivelmente a viabilizaram. No intuito de preservar o anonimato, os autores optaram deliberadamente por ocultar a identidade dos envolvidos. A reflexão foi embasada em livros e textos que abordam morte e bioética.

\section{Caso clínico}

A morte é inexorável, muitas vezes malogrando qualquer esforço médico de tentar adiá-la. Porém, a observação subjetiva de alguns casos sugere que certos pacientes aguardam determinados eventos para permitir-se morrer. $\mathrm{O}$ caso em questão se passou no HMSJP, na mesma cidade em que a paciente, de 83 anos, residia com sua filha há dois anos, desde que se tornou progressiva e totalmente dependente para atividades da vida diária devido a síndrome demencial vascular.

A internação ocorreu em abril de 2018, quando a paciente foi levada pela filha ao hospital por causa de quadro de confusão mental. Exames clínicos e complementares evidenciaram pneumonia broncoaspirativa. A filha cuidadora foi consultada sobre os valores da paciente e informada do quadro clínico e, após reflexão sobre a perda funcional total e progressiva da paciente, por decisão compartilhada, optou-se por medidas de conforto para morte digna e sem sofrimento, junto aos entes queridos.

A paciente permanecia confusa, e entre seus balbucios a única palavra compreensível era o nome da neta a quem era mais apegada. Como apenas uma das três filhas vivia na cidade, os familiares solicitaram sua transferência para a cidade natal, Palmas/PR, Brasil, onde residiam os demais parentes e a neta pela qual chamara. Enquanto tramitavam processos burocráticos para o translado, a condição da paciente piorou, com disfunções orgânicas secundárias à sepse pulmonar em curso, apresentando instabilidade hemodinâmica e disfunção ventilatória e renal, necessitando de morfina para controle da dispneia. Uma vez que essa progressão do quadro impossibilitava a transferência da paciente e que seus familiares não dispunham de meio de transporte para viajar até o hospital, decidiu-se que a filha cuidadora iria buscá-los.

A partir desse momento, a equipe multiprofissional tornou-se a única fonte de afeto e suporte social e espiritual que a paciente possuía naquele ambiente. Progressivamente, apesar das medidas paliativas, sua respiração tornou-se agônica, demandando sedação paliativa para conforto; clinicamente, a equipe estimou serem estes os últimos minutos ou horas de vida da paciente. No entanto, o quadro, que até então vinha rapidamente piorando, estabilizou-se sem qualquer medida distanásica, permanecendo sem alteração por dois dias. Às $16 \mathrm{~h}$ do dia 27 de abril, a neta pela qual a paciente tanto clamava no início do internamento chegou ao quarto da avó; às $16 \mathrm{~h} 10 \mathrm{~min}$ o quadro da paciente evoluiu para parada cardiorrespiratória, confortável, junto aos seus familiares e à equipe multidisciplinar.

\section{Discussão}

Esta argumentação é puramente filosófica e especulativa, visto que não há dados qualitativos ou quantitativos na literatura médica que provem relação causal entre a chegada ou presença de familiares ou a resolução de pendências pessoais e a evolução ao óbito. No entanto, pessoas que trabalham em hospitais, onde desfechos de morte são recorrentes, sabem que situações como essa ocorrem, embora sejam pouco relatadas. Os mais céticos, por outro lado, podem analisar estes casos como mera coincidência ou obra do acaso. Ainda assim, os poucos registros sobre o tema tornam este artigo singular na literatura médica, apesar de relatar apenas um caso.

O conceito de dor total, proposto por Cicely Saunders ${ }^{1}$ na década de 1960 no St. Joseph Hospice, na Inglaterra, pode auxiliar a analisar a questão. Um paciente cujos sintomas físicos estão controlados (sem dispneia, recebendo analgesia de horário, medidas de higiene brônquica etc.) pode permanecer com sintomas sociais, físicos, emocionais ou espirituais descontrolados, sendo possivelmente o motivo para que o paciente não se permita "partir".

Nessa concepção, desvincula-se saúde e ausência de dor e passa-se a compreender o indivíduo em 
sua totalidade, compreendendo todos os seus aspectos, inclusive espirituais. Vale salientar ainda que, por vezes, a espiritualidade é a forma de enfrentar a doença e aliviar o sofrimento ${ }^{2}$. Leonardo Boff aponta para o fato de que a espiritualidade vem sendo descoberta como dimensão profunda do humano, como o momento necessário para o desabrochar pleno de nossa individualização e como espaço da paz no meio dos conflitos e desolações sociais e existenciais ${ }^{3}$.

O confronto com doença grave lembra o ser humano da brevidade da vida e da urgência de projetos realmente importantes. Usualmente, nesse estágio final, o indivíduo, ao hierarquizar valores, percebe que as afetividades, os vínculos familiares e as relações humanas são o que há de realmente essencial. Saunders ${ }^{4}$ citava que pacientes procuram pessoas que se esforcem para entendê-los, e nesse sentido os sentimentos e atitudes da equipe multidisciplinar merecem ser compreendidos e trabalhados, a fim de contribuir para o alívio do sofrimento emocional e social. Elisabeth Kübler-Ross ${ }^{5}$, em "Sobre a morte e o morrer", destaca como a equipe assistente tende a negar a terminalidade de seus pacientes e a evitá-la. Isso gera no profissional reações de indiferença ou mesmo hostilidade que afetam os cuidados do paciente, e por isso necessitam ser trabalhadas 5 . Ainda neste âmbito de dor não fisica, a mesma autora mostra que muitas vezes a família reflete os estágios de luto que o paciente está vivenciando, e, mais uma vez, é papel da equipe assistente preparar os familiares para que aceitem mais suavemente o processo de separação.
A prática clínica mostra que nem tudo na medicina é previsível ou explicável. Melhoras súbitas ou falecimentos imcompreensivelmente adiados por vezes são acompanhados da necessidade de encontros com poderes medicinais, ou seja, aqueles que podem curar. Por isso é importante também lembrar que cada indivíduo faz parte de uma teia de relações e afetos que por vezes é o apoio de muitos. Quando um elemento desta conexão morre, aspectos da vida de outros, interligados nesta teia, morrem também. Ao compreendermos esta estrutura viva e conectada de vínculos e afetos, entendemos também a importância de eventos de ressignificação e de reencontros, tanto para os que partem quanto para os que ficam ${ }^{5}$.

\section{Considerações finais}

Não podemos afinal entender questões que tratam de algo ainda imensurável, mas reconhecer a existência da melhora clínica inexplicável a fim de permitir encontros já é primeiro passo a ser dado pelas equipes médicas e multidisciplinares que cuidam de pacientes em fim de vida. Trata-se de evento que ainda não pode ser tecnicamente explicado, mas cuja ocorrência é constatada na prática de cuidados paliativos. Relatos como este ainda são exceção na literatura, talvez porque a medicina atual foque demais protocolos e escalas, talvez pela complexidade da tentativa de explicá-los. De certo modo, por relatar um único caso, o artigo peca por "peso científico"; porém, é preciso ressaltar a difícil tarefa de escrever sobre algo tão subjetivo.

\section{Referências}

1. Saunders C. Hospice and palliative care: an interdisciplinary approach. Londres: Edward Arnold; 1990.

2. Evangelista CB, Lopes MEL, Costa SFG, Batista PSS, Batista JBV, Oliveira AMM. Cuidados paliativos e espiritualidade: revisão integrativa da literatura. Rev Bras Enferm [Internet]. 2016 [acesso 16 abr 2019];69(3):591-601. DOI: 10.1590/0034-7167.2016690324i

3. Boff L. Espiritualidade: um caminho de transformação. Rio de Janeiro: Sextante; 2001. p. 18.

4. Saunders C. Velai comigo: inspiração para uma vida em cuidados paliativos. Lisboa: Universidade Católica Editora; 2013.

5. Kübler-Ross E. Sobre a morte e o morrer: o que os doentes terminais têm para ensinar a médicos, enfermeiras, religiosos e aos seus próprios parentes. São Paulo: WMF Martins Fontes; 2008.

\section{Participação dos autores}

Adriana Rodrigues da Silva Utida orientou o trabalho e complementou a versão a ser publicada. Alexandre da Silva Faco Junior elaborou a introdução e a discussão. Geraldo Karam Joaquim Mousfi redigiu o relato de caso.

\section{Correspondência \\ Alexandre da Silva Faco Junior - Hospital Municipal e Maternidade São José. Rua Paulino de Siqueira Cortês, 2.304, São Pedro CEP 83005-020. São José dos Pinhais/PR, Brasil.}

Adriana Rodrigues da Silva Utida - Mestre - adrianautida@hotmail.com (iD) 0000-0003-1183-0555

Alexandre da Silva Faco Junior - Especialista - alexandre.faco@hotmail.com

(iD) 0000-0003-3907-8975

Geraldo Karam Joaquim Mousfi - Graduado - geraldokjm@yahoo.com.br

(iD) $0000-0002-2441-8183$

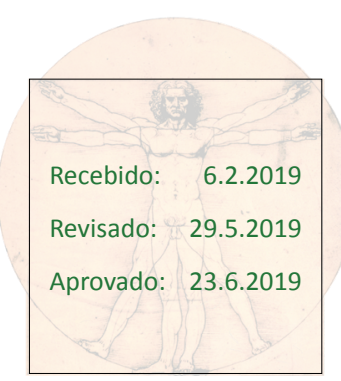

